\title{
Immunocytochemical localization of leptin hormone in the neurosecretory cells of brain-suboesophageal ganglion complex of tropical tasar silkworm, Antheraea mylitta (D.) eco-race Bhandara
}

\author{
Deepak D. Barsagade ${ }^{1}$, Shruti A. Gharade ${ }^{2, *}$ and Vikas G. Barsagade ${ }^{3}$ \\ ${ }^{1}$ P.G. Department of Zoology, MJF Educational Campus, RTM Nagpur University, Nagpur 440 033, India \\ ${ }^{2}$ Department of Zoology, R. S. Bidkar Arts, Commerce and Science College, Hinganghat Dist., Wardha 442 301, India \\ ${ }^{3}$ Department of Zoology, Nabira Mahavidyalaya, Katol Dist., Nagpur 441 302, India
}

Leptin is a peripheral agent known for its function in feeding behaviour in vertebrates. In this study, we demonstrated leptin immunoreactivity in the brain and suboesophageal ganglion (SOG) of tropical tasar silkworm, Antheraea mylitta (D.) by immunohistochemistry using polyclonal antibody against mammalian leptin. Leptin immunoreactivity was not observed in the adult brain, whereas, intense reactivity was detected in the single neuronal group of cells in SOG. This study provides an essential groundwork to further elucidate the involvement of leptin in insect development and appetite regulatory systems of tropical tasar silkworm, Antheraea mylitta (D.) as well as in other insects.

Keywords: Antheraea mylitta, leptin, suboesophageal ganglion, tasar silkworm.

IT is well documented that the product of the human obesity (ob) gene - leptin, appears as an indicator of energy balance, body weight, growth, metabolism and reproduction in vertebrates ${ }^{1-4}$. In invertebrates, several bioactive peptides are detected in the neuroendocrine tissues regulating feeding, growth and reproduction ${ }^{5-10}$. Particularly in insects, most of the neuropeptides such as pancreatic polypeptide, neuropeptide Y, peptide YY, insulin-like peptide, adipokinetic hormone, are involved in the food intake regulation, energy homeostasis, growth and reproduction $^{11-20}$. A group of FXPRLa (Phe-X-Pro-Arg-LeuNH2), a five amide peptides like DH (diapause hormone) and PBAN (pheromone biosynthesis activating peptide) are located which influence many physiological processes within insects ${ }^{21-24}$. DH and PBAN immunoreactive cells were observed in the suboesophageal ganglion (SOG) and suggested to be involved in other processes apart from induction of embryonic diapause and pheromone produc-

*For correspondence. (e-mail: shruti.gharade@gmail.com) tion $^{23}$. In tasar silkworm Antheraea mylitta, the neuropeptide NPY, FMRF amide are localized in the brain ${ }^{25}$.

The neurosecretory cells (NSC) of SOG are reported to release several neurohormonal secretions in the retrocerebral complex and peripheral areas in insect's head. In silkworm, Bombyx mori, the NSC in SOG were reported to produce $\mathrm{DH}$ and PBAN which act on the developing ovary and produce diapause eggs ${ }^{22,23}$. In virgin female silk moth, sex hormone productions induced by the activity of PBAN is well known ${ }^{26}$.

However, no efforts have been made to demonstrate the localization of leptin hormone immunohistochemically in insects including silkworms. The present work was therefore, undertaken to examine the leptin immunoreactivity in the brain and SOG of the tasar silkworm $A$. mylitta, against the antisera leptin to elucidate the presence of leptin in the silkworm.

\section{Materials and methods}

\section{Insect collection and tissue processing}

Selected healthy cocoons of wild tasar silkworm, Antheraea mylitta (D.) eco-race Bhandara, from the forest of Gadchiroli, were collected and maintained at the insectaries of the Department of Zoology, RTM Nagpur University, Nagpur, India. Collected cocoons were incubated up to adult emergence particularly under optimum temperature $\left(20^{\circ} \mathrm{C}-30^{\circ} \mathrm{C}\right)$ and relative humidity $(65 \%-80 \%)$. The selected adult silkmoths were anesthetized with chloroform soaked in cotton pad and the brains along with SOG were dissected out in Ringer's solution. The dissected brain and SOG were immediately fixed in the aqueous Bouin's fixative for 18-24 h. Additional tissue (brain and SOG) was incubated overnight for cryopreservation at $4{ }^{\circ} \mathrm{C}$, in sucrose solution $10 \%(2 \mathrm{~h}), 20 \%(2 \mathrm{~h})$, and $30 \%$ (overnight) with expanding $\mathrm{CO}_{2}$, and embedded in 


\section{RESEARCH ARTICLES}

polyvinyl pyrolidone solution. Serial sections $(10 \mu \mathrm{m}$, lateral planes) were cut on a cryostat (CM1850, Leica). Mounted sections on poly-L-lysine-coated slides were further subjected to leptin immunocytochemical labelling as described below. Four brains fixed in Bouin's fixative were processed for paraffin embedding, cut in the lateral plane and used for Bergmann's chrome-alum-haematoxylin phloxine (CHP) staining.

\section{Leptin immunocytochemistry}

Streptavidin-biotin-peroxidase method was performed as per previous report ${ }^{25}$, with given minor modifications to localize leptin in the brain and SOG sections.

Sections were briefly washed in phosphate-buffered saline (PBS) ( $\mathrm{pH} 7.45)$ for $15 \mathrm{~min}$ and preincubated with BSA (bovine serum albumin) in PBS, then incubated with anti-leptin polyclonal antibodies (L 3410 Sigma) for $2 \mathrm{~h}$ at $25^{\circ} \mathrm{C}$. The primary antiserum was diluted in PBS ( $1: 5000$ ) containing $0.3 \%$ Triton $X-100$ and $1 \%$ BSA. The sections then were rinsed in PBS for $10 \mathrm{~min}$ and exposed with biotinylated anti-rabbit IgG (Sigma; $1: 100)$ for $1 \mathrm{~h}$, followed by ExtrAvidin-peroxidase conjugate (Sigma; $1: 100$ ) for $60 \mathrm{~min}$. After another rinse in PBS, reaction products were visualized with chromogen (3-amino-9-ethyl carbazole). Sections were washed in water and finally mounted in glycerol gelatin media. To confirm the histological neuronal areas some sections were counterstained with Bergmann's CHP. Control procedures performed to test the specificity of anti-leptin in the brain and SOG, like omission of the primary antibody from reaction and preadsorption of the antibody with recombinant mouse leptin (Sigma), resulted in loss of immunoreaction (Figure 1).

\section{Results}

A noticeable difference was reported in the neuroanatomical pattern of the brain and SOG of the larva A. mylitta. In larva, SOG was connected to the brain by a pair of long circumoesophageal connectives, while in the adult, SOG was completely fused with the tritocerebral lobes of

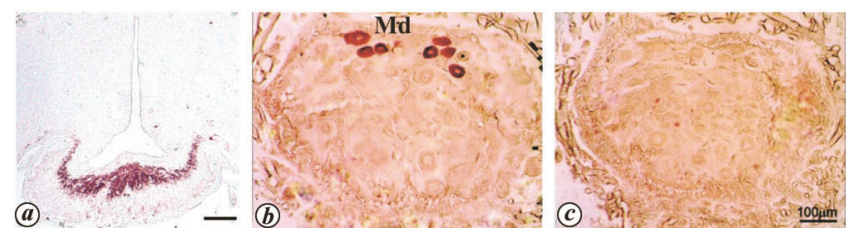

Figure 1. Positive control section showing leptin immunoreactivity in the median eminence in $(\boldsymbol{a})$ mice brain and $(\boldsymbol{b})$ cells of mandibular (Md) in suboesophageal ganglion (SOG) in the silkworm. $c$, No leptin immunoreactivity was observed in the Md neurons in the section incubated with antibodies preadsorbed with leptin. Scale bar $=50 \mu \mathrm{m}$ in $\boldsymbol{a}$ $100 \mu \mathrm{m}$ in $\boldsymbol{b}$ and $\boldsymbol{c}$. the brain $^{25,27,28}$ (Figure 2). Different cell groups in the brain and SOG of A. mylitta were identified on the basis of previous lepidopteran histological studies ${ }^{25,27,28}$ (Figures $3 a, b$ and 4).

Brain in the adult silkworm consists of protocerebral, deutocerebral and tritocerebral lobes interconnected with
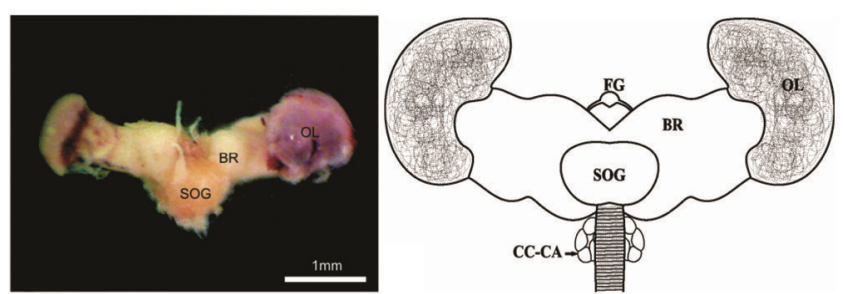

Figure 2. Figure shows a ventral view of Antheraea mylitta brainSOG complex indicating brain (BR), optic lobe (OL) and SOG. Different regions are represented in the schematic drawings of brain-SOG complex in A. mylitta. CC-CA, Corpora cardiaca-corpora allata complex; FG, Frontal ganglion. Scale bar $=1 \mathrm{~mm}$.

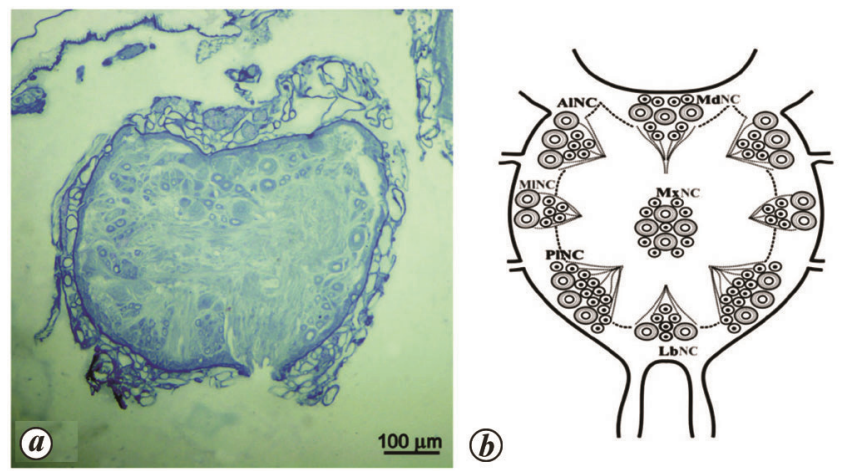

Figure 3. a, Lateral section of SOG showing different neuronal groups in the Bergmann's chrome-alum-haematoxylin phloxine (CHP) staining. $\boldsymbol{b}$, Diagrammatic representation of SOG showing various groups of neurosecretory cells in adult brain. MdNC, Mandibular neurosecretory cells; MxNC, Maxillary neurosecretory cells; LbNC, Labial neurosecretory cells; AlNC, Antero-lateral neurosecretory cells; PINC, Postero-lateral neurosecretory cells; MINC, Mid-lateral neurosecretory cells. Scale bar $=100 \mu \mathrm{m}$.

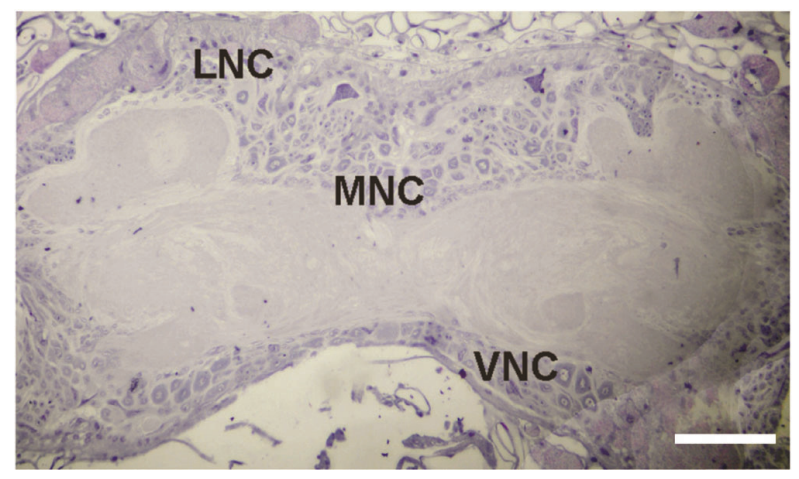

Figure 4. Lateral section showing different neuronal groups in the brain with Bergmann's CHP staining. LNC, Lateral neurosecretory cells; MNC, medial neurosecretory cells; VNC, Ventral neurosecretory cells. Scale bar $=100 \mu \mathrm{m}$. 
Table 1. Groups of cells, number of immunoreactive cells and size of leptin immunoreactive cells in suboesophageal ganglion (SOG) of Antheraea mylitta

\begin{tabular}{|c|c|c|c|c|}
\hline \multirow[b]{2}{*}{ Groups of cells } & \multirow[b]{2}{*}{ Immunoreactive groups } & \multirow[b]{2}{*}{ Number of immunoreactive cells } & \multicolumn{2}{|c|}{ Cell size $(\mu \mathrm{m})$} \\
\hline & & & Nucleus diameter & Cell diameter \\
\hline Md & + & $8 \pm 1$ & $34.09 \pm 0.41$ & $11.99 \pm 0.41$ \\
\hline Mx & - & - & - & - \\
\hline $\mathrm{Lb}$ & - & - & - & - \\
\hline AlNC & - & - & - & - \\
\hline $\mathrm{MINC}$ & - & - & - & - \\
\hline $\mathrm{PINC}$ & - & - & - & - \\
\hline
\end{tabular}

Md, Mandibular neurosecretory cells; Mx, Maxillary neurosecretory cells; Lb, Labial neurosecretory cells; AlNC, Antero-lateral neurosecretory cells; PINC, Postero-lateral neurosecretory cells; MINC, Mid-lateral neurosecretory cells. Dash (-) refers absent of cells.

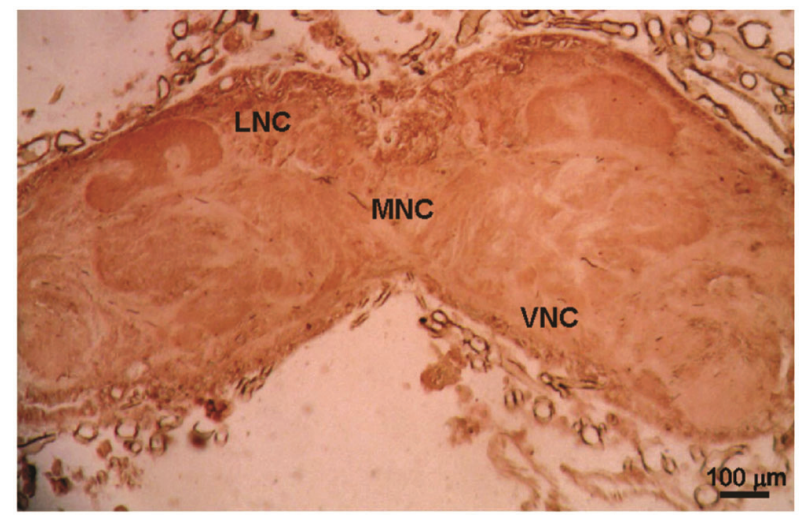

Figure 5. Lateral sections of brain processes for leptin immunoreactivity. No leptin immunoreactive cells were observed in the entire brain (LNC, MNC and VNC). Scale bar $=100 \mu \mathrm{m}$.

series of neurosecretory cell axons ${ }^{25}$. Histomorphologically, four groups of neuronal cells were identified in the brain areas of adult $A$. mylitta, viz. medial neurosecretory cells (MNC), lateral neurosecretory cells (LNC), posterior neurosecretory cells (PNC) and ventral neurosecretory cells $(\mathrm{VNC})^{25}$ (Figure 4$)$.

\section{Leptin immunoreactivity in the brain and $S O G$}

As described earlier by Barsagade et al. ${ }^{25}$, three types of neurosecretory cells, viz. A, B and C cells were present in MNC, LNC, PNC and VNC groups of adult silkworm brain $^{25,28}$. Cryosections of adult brain were processed with anti-leptin antibody. No leptin immunoreactivity was detected in any neurosecretory cells of brain in adult silkworm (Figure 5).

Six groups of neurosecretory cells in SOG, viz. a mandibular neurosecretory cells (MdNC), maxillary (MxNC), labial (LbNC), paired antero-lateral (AlNC), paired midlateral (MINC) and paired postero-lateral neurosecretory cells (PINC) were identified. Brain cryosections collected from adult silkmoth were processed for immunohistology using anti-leptin antibody. Among the six groups in SOG, one group of neurosecretory cells were leptin positive, i.e. MdNC and no leptin immunoreactions were observed

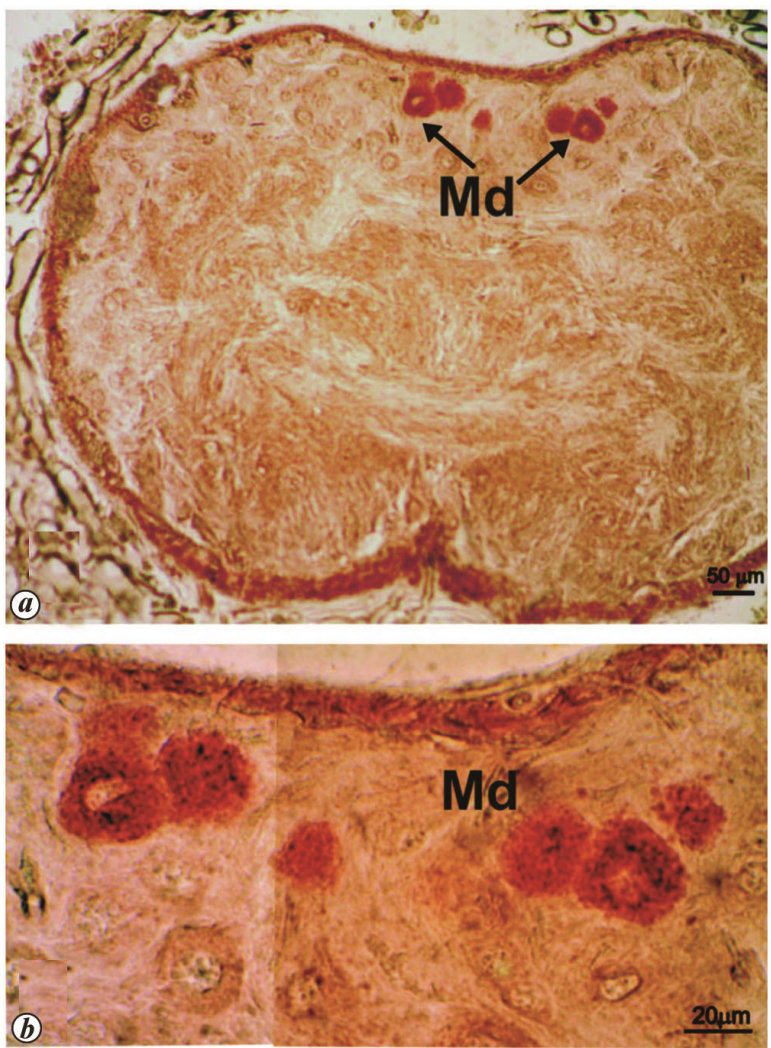

Figure 6. Lateral section of SOG showing the leptin immunoreactive cells in the Md groups (arrows, $\boldsymbol{a}$ ). Region Md of section (a) magnified in section $(\boldsymbol{b})$. Scale bar $=50 \mu \mathrm{m}$ in $(\boldsymbol{a}) ; 20 \mu \mathrm{m}$ in $(\boldsymbol{b})$.

in MxNC, LbNC, AlNC, MINC and PINC (Figure $6 a$ and $b)$. However, leptin immunoreactive cells were noticed in the dorso-medial region in SOG. On the basis of the cell size (cell diameter and nuclear diameter), these cells were classified into A, B, C cells. Numerous intense to moderate immunoreactive $\mathrm{C}$ cells were observed in the $\mathrm{Md}$ neuronal group (Figure 6; Table 1). No leptin immunoreactive cells were detected in Mx and Lb (Figure 6 and Table 1).

\section{Discussion}

In the present study, distribution of leptin immunoreactive elements was examined in the brain and SOG of the 
cephalic neuroendocrine system of tasar silkworm $A$. mylitta by using polyclonal anti-leptin antibody.

Various types of NSC, forming distinct groups were identified on the basis of previous studies ${ }^{25,27,28}$. Similar anatomical pattern of central nervous system in the pupa of silkworm and tobacco hornworm have been already reported $^{29,30}$. Thus, similar terminology was used in the present study proposed by Copenhaver and Truman ${ }^{29}$. Sato et al. ${ }^{31}$ explained the presence of $\mathrm{Md}, \mathrm{Mx}, \mathrm{Lb}$ and lateral (L) groups of NSC in SOG of Bombyx mori ${ }^{22}$ and black cutworm moth Agrotis ipsio ${ }^{23}$. Distinct cell groups, i.e. $\mathrm{Md}, \mathrm{Mx}$ and $\mathrm{Lb}$ were already noticed in the SOG of Achaea janata $^{32}$. Recently, Hiroshi et al. ${ }^{8}$ described the presence of $\mathrm{Md}, \mathrm{Mx}$ and $\mathrm{Lb}$ neuronal cell groups in the SOG of tussock moth, Orgyia thyellina. In the present study, position of the NSC groups was found similar to the earlier studies ${ }^{8}$. Therefore, similar nomenclature has been used for the immunoreactive cell groups located in the anterior, middle and posterior regions and termed as $\mathrm{Mx}, \mathrm{Lb}$ and $\mathrm{Md}$ groups in SOG of $A$. mylitta.

In insects, various neuromeres such as $\mathrm{Md}, \mathrm{Mx}$ and $\mathrm{Lb}$ segments are involved to develop the $\mathrm{SOG}^{24}$. These three cluster of cells bring input of signals from their respective organs lying on the $\mathrm{Md}, \mathrm{Mx}$ and $\mathrm{Lb}$ appendages in Manduca sexta ${ }^{24}$, Heliothis zea ${ }^{33,34}$, Bombyx mori ${ }^{31,35,36}$. In addition to this, SOG receives input from mouth parts, i.e. labral, $\mathrm{Md}, \mathrm{Mx}, \mathrm{Lb}$, antennal nerves and gustatory sensilla which are involved in the gustatory processing ${ }^{37}$. Moreover, Md seems to be arborized in the anterior portion of the SOG in M. sexta ${ }^{24}$.

Role of SOG in the feeding behaviour in insects has been well described in the earlier studies ${ }^{38}$. SOG containing neuronal cells projected their axonal terminals to the ganglions of insect's head and gustatory organ. Whereas, these NSC are closely associated with the axon terminals of gustatory sensory neurons within SOG, indicate the involvement of cells in the mediation of taste information and feeding regulation ${ }^{38}$.

Earlier immunocytochemical localization of serotonin, dopamine and Gamma aminobutyric acid (GABA) in SOG neurosecretory cells was reported in water beetle, Cybister tripunctatus $^{39}$. In ventral midline of the SOG, of the silkworm, Bombyx mori, Ichikawa ${ }^{36}$ reported three different groups of cells. In Heliothis zea, PBANcontaining three similar groups of NCS in the SOG were also reported ${ }^{33}$. Moreover, in Helicoverpa armigera, histological localization of FXPRL amide neuropeptides, $\mathrm{DH}$ and PBAN were reported in the $\mathrm{SOG}^{40}$. During the present study, eight leptin-neurosecretory cells in the $\mathrm{Md}$ region were noticed. Immunoreactive sections observed $\mathrm{C}$ type of cells in SOG of A. mylitta (Table 1). Present observation suggested that leptin in Md cells within SOG might be involved in the transmission of gustatory and sensory information.

Neurosecretory cells in the SOG of lepidopteran insects secrete several neurohormones that act on the developing ovary to induce diapause eggs ${ }^{21-23}$. Involvement of DH, a peptide belonging to the FXPRL amide neuropeptide family, in the embryonic diapause, and developing ovaries during pupal-adult development in females has been well discussed ${ }^{41}$. Furthermore, DH is also located in the DH-PBAN-producing neurosecretory cells (DHPCs) within SOG ${ }^{41}$. Presence of pheromone biosynthesis activating neuropeptide like immunoreactivity in the three clusters within SOG indicates the function of peptide in the regulation of sex pheromones ${ }^{23,31}$. During the present study it has been found that the leptin immunoreactive cells are located in the Md region. These data on leptin expression in the adult SOG suggested that hormones might be involved in the activity related to reproduction as the adult moths are non feeders.

Based on the earlier reports on insects and A. mylitta, results of the present study indicate that leptin is released from the SOG and might be involved in physiological functions such as energy homeostasis and reproductive maturation in the silkworm A. mylitta. In contrast, absence of leptin in the brain of adult silkmoth indicates that it is strictly peripheral in origin and might act as peripheral signal molecules to regulate brain endocrine and other physiological mechanism. Till date, no function had been assigned to leptin in insects and our study is perhaps the first report on leptin and further research is, therefore inevitable.

1. Zhang, Y., Proenca, R., Maffei, M., Barone, M., Leopold, L. and Friedman, J. M., Positional cloning of the mouse obese gene and its human homologue. Nature, 1994, 372, 425-431.

2. Ahima, R. S., Prabakaran, D., Mantzoros, C., Qu, D., Lowell, B., Flier-Maratos, E. and Flier, J. S., Role of leptin in the neuroendocrine response to fasting. Nature, 1996, 382, 250-252.

3. Tinoco, A. et al., Leptin expression is rhythmic in brain and liver of goldfish (Carassius auratus). Role of feeding time. Gen. Comp. Endocr., 2014, 1(204), 239-247.

4. Mietlicki-Baase, E. et al., Cooperative interaction between leptin and amylin signaling in the ventral tegmental area for the control of food intake. Am. J. Physiol. - Endocr. Metab., 2015, 308(12), 1116-1122; doi:10.1152/ajpendo.00087.2015.

5. Loughton, B. G. and Saleuddin, A. S. M. (eds), Neurobiology and Endocrinology of Selected Invertebrates, Captus University Publications, North York, Canada, 1990.

6. Naya, S. et al., Eclosion hormone like immunoreactivity in the nervous system of Bombyx mori (Lepidoptera: Bombycidae) and Antheraea yamamai (Lepidoptera: Saturniidae) before after hatching. Eur. J. Entomol., 1994, 91, 189-196.

7. Nässel, D. and Wegener, C., A comparative review of short and long neuropeptide $\mathrm{F}$ signaling in invertebrates: any similarities to vertebrate neuropeptide Y signaling? Peptides, 2011, 32, 13351355.

8. Hiroshi, U., Yukiko, S., Kyohei, Y., Yoshiomi, K. and Kunihiro, S., An FXPRL amide neuropeptide induces seasonal reproductive polyphenism underlying a life history tradeoff in the Tussock moth. PLoS ONE, 2011, 6(8), 1-10.

9. Landau, M., Biggers, W. J. and Laufer, H., Invertebrate endocrinology, Comprehensive physiology, 2011.

10. Tembhare, D., Invertebrate Endocrinology, Himalaya publishing House, Mumbai, India, 2012, 1 st edn. 
11. Kramer, K. J., Vertebrate hormones in insects. In Comprehensive Insect Physiology, Biochemistry, and Pharmacology, Vol. 7 (eds Kerkut, G. A. and Gilbert, L. I.), Pergamon Press, Oxford, UK, 1985, pp. 511-536.

12. Raabe, M., Comparative immunocytochemical study of release sites of insulin, glucagon and AKH-like products in Locusta migratoria, Periplaneta americana, and Carausius morosus. Cell Tissue Res., 1986, 245, 267-271.

13. Hazelwood, R., The pancreatic polypeptide (PP-fold) family: gastrointestinal, vascular, and feeding behavioral implications. Proc. Soc. Exp. Biol. Med., 1993, 202, 44-63.

14. Hu, Y. et al., Identification of a novel hypothalamic neuropeptide Y receptor associated with feeding behavior. J. Biol. Chem., 1996, 271, 26315-26319.

15. Gade, G. and Auerswald, L., Insect neuropeptides regulating substrate mobilization. S. Afr. J. Zoo., 1998, 33, 65-70.

16. Nassel, D. R., Tachykinin-related peptides in invertebrates: a review. Peptides, 1999, 20, 141-158.

17. Nassel, D. R., Neuropeptides in the nervous system of Drosophila and other insect: multiple role as neuromodulators and neurohormones. Prog. Neurobiol., 2002, 68, 1-84.

18. Predel, R., Peptidergic neurohemal system of an insect: mass spectrometric morphology. J. Comp. Neurol., 2001, 436, 363-375.

19. Nichols, R., Signaling pathways and physiological function of Drosophila melanogaster FMRF amide-related peptides. Annu. Rev. Entomol., 2003, 48, 485-503.

20. Patel, H. et al., Reprint of the distribution and physiological effects of three evolutionarily and sequence-related neuropeptides in Rhodnius prolixus: Adipokinetic hormone, corazonin and adipokinetic hormone/corazonin-related peptide. Gen. Comp. Endocr., 2014, 203, 307-314.

21. Fukuda, S. and Takeuchi, S., Diapause factor producing cells in the suboesophageal ganglion of the silkworm Bombyx mori L. Proc. Jpn Acad., 1967, 43, 51-56.

22. Fukuda, S. and Takeuchi, S., Studies on the diapuse factor producing cells in the sub-osophageal ganglion of the silk worm, Bombyx mori L. Embryologia (Nagoya), 1967, 9, 333-353.

23. Ichikawa, T., Hasegawa, K., Shimizu, I., Katsuno, K., Kataoka, H. and Suzuki, A., Structure of neurosecretory cells with immunoreactive diapause hormone and pheromone biosynthesis activating neuropeptide in the silkworm, Bombyx mori. Zool. Sci., 1995, 12, 703-712.

24. Davis, N. T., Homberg, U., Teal, P. E. A., Altstein, M., Agricola, H. J. and Hildebrand, J. G., Neuroanatomy and immunocytochemistry of the median neuroendocrine cells of suboesophageal ganglion of the tobacco hawkmoth, Manduca Sexta. Immunoreactivities to PBAN and other peptides. Microsc. Res. Techniq., 1996, 35, 201-229

25. Barsagade, D. D., Rathee, S. D. and Tembhare, D. B., Structure of cephalic neuroendocrine system and immunocytochemical lacalization of neurohormones FMRF amide and neuropeptide-Y (NPY) in the cerebral neurosecretory cells in the tropical tasar silkworm, Antheraea mylitta (D.). In Applications of Biotechnology in Sericulture, Stardium Press (India), New Delhi, 2011, pp. 189-202.

26. Ando, T., Hase, T., Funayoshi, A., Arima, R. and Uchiyama, M., Sex pheromone biosynthesis from ${ }^{14} \mathrm{C}$-hexadecanoic acid in the silkworm moth. Agric. Biol. Chem., 1988, 52, 141-147.

27. Barsagade, D. and Gharade, S., Ultrastructural studies on the neurosecretory cells in the pars intercerebralis of larvae of tasar silkworm, Antheraea mylitta (D) eco-race Bhandara (Lepidoptera: Saturniidae). Int. J. Indust. Entomol., 2014, 29(1), 120-127.

28. Tembhare, D. and Barsagade, D., Cephalic neuroendocrine system in the tropical tasar silkworm, Antheraea mylitta (D) (Lepidoptera:
Saturniidae): metamorphic and sericotropic functions. Int. J. Wild Silkmoth Silk, 2000, 4, 1-9.

29. Copenhaver, P. F. and Truman, J. W., Metamorphosis of the cerebral neuroendocrine system in the moth Manduca sexta. J. Neurol., 1986, 54, 814-826.

30. Huetteroth, W., el Jundi, S. and Schachtner, J., 3D-reconstructions and virtual 4D-visualization to study metamorphic brain development in the sphinx moth Manduca sexta. Front. Syst. Neurosci., 2010, 4(7), 1-15.

31. Sato, Y., Ikeda, M. and Yamashita, O., Neurosecretory cells expressing the gene for common precursor for diapause hormone and pheromone biosynthesis activating neuropeptide in the suboesophageal ganglion of the silkworm, Bombyx mori. Gen. Comp. Endocr., 1994, 96, 27-36.

32. Ajitha, V. S. and Muraleedharan, D., Tissue localization and partial characterization of pheromone biosynthesis activating neuropeptide in Achaea janata. J. Biosci., 2005, 30(2), 191-200.

33. Blackburn, M., Kingan, T. G., Raina, A. K. and Ma, M. C., Colocalization and differential expression of PBAN-and FMRF amide - like immuno reactivity in the suboesophageal ganglion of Heliothis zea during development. Arch. Insect. Biochem. Physiol., 1992, 21, 225-238.

34. Altman, J. S. and Kien, J., Functional organization of the suboesophageal ganglion in arthropods. In Arthropod Brain: Its Evolution, Development, Structure and Functions (ed. Gupta, A. P.), Wiley, New York, 1987, pp. 265-301.

35. Mitsumasu, K. et al., Molecular cloning and characterization of cDNAs encoding dopamine receptor-1 and -2 from brainsuboesophageal ganglion of the silkworm, Bombyx mori. Insect. Mol. Biol., 2008, 17, 185-195.

36. Ichikawa, T., Architecture of cerebral neurosecretory cell systems in the silkworm Bombyx mori. J. Exp. Biol., 1991, 161, 217-237.

37. Mitchell, B., Itagaki, H. and Pascale, R., Peripheral and central structures involved in insect gustation. Microsc. Res. Techniq., 1999, 47, 401-415.

38. Bader, R., Colomb, J., Pankratz, B., Schrock, A., Stocker, R. F. and Pankratz, M. J., Genetic dissection of neural circuit anatomy underlying feeding behavior in Drosophila: distinct classes of hugin-expressing neurons. J. Comp. Neurol., 2007, 502(5), 848856.

39. Pawar, K. R. and Tembhare, D. B., Immunocytochemical localization of some neurotransmitters in the neurosecretory cells in the brain and ventral ganglia of the water beetle, Cybister tripunctatus O1. (Coleoptera: Dytiscidae). J. Ent. Res., 2010, 34(3), 181-185.

40. Sun, J.-S., Zhang, T.-Y., Zhang, Q.-R. and Xu, W. H., Effect of the brain and suboesophageal ganglion on pupal development in Helicoverpa armigera through regulation of FXPRL amide neuropeptides. Regul. Peptides, 2003, 116, 163-171.

41. Morita, A., Niimi, T. and Yamashita, O., Physiological differentiation of DH-PBAN-producing neurosecretory cells in the silkworm embryo. J. Insect. Physiol., 2003, 49(12), 1093-1102.

ACKNOWLEDGEMENTS. Present study was funded by University Grant Commission (UGC) through a research project (No. 36-202/ 2008) and for Rajiv Gandhi National Fellowship to S.A.G. We also thank Dr D. B. Tembhare, Ex-Professor and Head, Department of Zoology, RTM Nagpur University, for critical reading of the manuscript and valuable comments.

Received 21 August 2020; revised accepted 19 January 2021

doi: $10.18520 / \mathrm{cs} / \mathrm{v} 120 / \mathrm{i} 10 / 1611-1615$ 